\title{
Effect of Silane Coupling Agent on the Flexural Property of Glass Fiber Reinforced Composite Film
}

\author{
Hye-Hyun Kim, Si-Young Kim, Dae-Hee Kim, Chae-Young Oh, Nam-Ju Jo* \\ Department of Polymer Science \& Engineering, Pusan National University, Busan, Korea \\ Email: ${ }^{*}$ namjujo@pusan.ac.kr
}

Received August 2014

\begin{abstract}
Transparent glass fiber reinforced composites films ware fabricated by UV light induced chemical crosslinking of composite materials consisting of glass fiber and UV curable resin in film state. In order to apply film to flexible device, excellent flexural property is required, then the delamination should not occurred between glass fiber and UV curable resin when film is bent. To minimize delamination and improve the interfacial adhesion at interface between glass fiber and UV curable resin, the $\gamma$-aminopropyl triethoxy silane and $\gamma$-glycid oxypropyl trimethoxy silane were applied for the surface treatment of glass fibers. Silanization of glass fiber surface was checked by scanning electron microscopy and the degree of delamination of composite film was confirmed through the bending test, ASTEM290-96a, used by haze meter.
\end{abstract}

\section{Keywords}

Glass Fiber, Silane, UV Curable Resin, Composite, Flexural Property, Haze

\section{Introduction}

Glass fiber is the most common reinforcing fiber for polymeric matrix composite. The principal advantages of glass fiber are low cost, high tensile strength, high chemical resistance, and excellent insulating property. Fiberreinforced polymer composites have seen a rapid rise in use in the past 30 years, due to their high strength and stiffness and light weight, compared with more traditional structural materials, such as steel and aluminum. The reason for this superior performance is the synergistic combination of the two, or more, constituent phases. This synergy is brought about by the interaction between the fibers and the polymeric matrix [1].

However, most of the fiber-reinforced polymer composites have been used as structural materials. They have not been tried for application to optical films in thin film transistor (TFT) liquid crystal display or flexible substrate in organic light emitting diodes (OLEDs).

For these applications, the matching of the refractive index of matrix and glass fiber should be essentially required for achieving transparent composite films. In addition, when composite film is bent, the optical property

\footnotetext{
"Corresponding author.
}

How to cite this paper: Kim, H.-H., Kim, S.-Y., Kim, D.-H., Oh, C.-Y. and Jo, N.-J. (2014) Effect of Silane Coupling Agent on the Flexural Property of Glass Fiber Reinforced Composite Film. Journal of Materials Science and Chemical Engineering, 2, 38-42. http://dx.doi.org/10.4236/msce.2014.210006 
should be equal. In other words, delamination should not be occurred between glass fiber and matrix resin, and this phenomenon is highly related with interfacial adhesion between glass fiber and matrix [2].

It is well known that the interphase plays a key role in determining mechanical interfacial properties of composites. The efficiency of the stress transfer between fibers and matrix is determined not only by molecular interaction at interface, but also by the properties of the formed interphase, in particular, its thickness and strength [3] [4].

One of the effective ways of creating interphase and, in this way, controlling composite properties is fiber surface treatment, using sizings and film formers or coupling agents.

To improve the interfacial adhesion at interface between the glass fibers and matrix resin, silane coupling agents were used formerly on the fibers [5]. At interface between the glass fibers and the silane coupling agent, the hydroxyl groups of the silanes and those of the glass fiber surface can react with each other through siloxane bonding or hydrogen bonding, as seen in Figure $\mathbf{1}$ which indicated the adhesion process of the silane coupling agents onto glass fibers [6] [7].

The aim for this work is to find out the relationship between flexural property of composite film and optical property as a result of composite film fabrication based on glass fiber processed by various silanes coupling agent.

\section{Experimental}

\subsection{Materials}

E-glass fiber (56 $\times 56$ count $/ 25 \mathrm{~mm}, 48 \mathrm{~g} / \mathrm{m}^{2}$ ) used in this work was supplied from Nittobo Asco Glass Fiber Co. Ltd.. And e-glass fiber is treated with acrylic silane compound [8]. For the matrix resin, fluorene acrylate and urethane acrylate were used. Both are provided from Osaka Gas Chemical Co. and SK Cytec. And 1-hydroxy cyclohexyl phenyl ketone (HCPK) was used as photoinitiator. Silane coupling agents, $\boldsymbol{\gamma}$-aminopropyltriethoxy silane (APS) and $\gamma$-glycidoxypropyltrimethoxy silane (GPS) are purchased from Sigma Aldrich. The chemical structures of APS and GPS are given in Figure 2.

\subsection{Silanization of Glass Fiber}

In order to treat silane, the glass fiber was fired at first under an ambient atmosphere at $500^{\circ} \mathbf{C}$ for $2 \mathrm{~h}$ to burn out the organic sizing agent coated onto its surface. Silane coupling agents were diluted to $1 \mathrm{wt} \%$ using the co-solvents of methanol and deionized water with the ratio of methanol/water $=80 / 20 \mathrm{wt} \%$. A silanol group is usually unstable in the presence of water, but it is stable in weakly acidic solution. Aminosilanes and glycidylsilanes are an exception because the amino group and glycidyl group help to stabilize the silane in water. Next, the hydrolysis of the silane coupling agent was carried out for $30 \mathrm{~min}$, and glass fibers were dipped in the hydrolyzed silane solution for $30 \mathrm{~min}$. And it was dried at $110^{\circ} \mathrm{C}$ for $5 \mathrm{~min}$, followed by $24 \mathrm{~h}$ at room temperature.

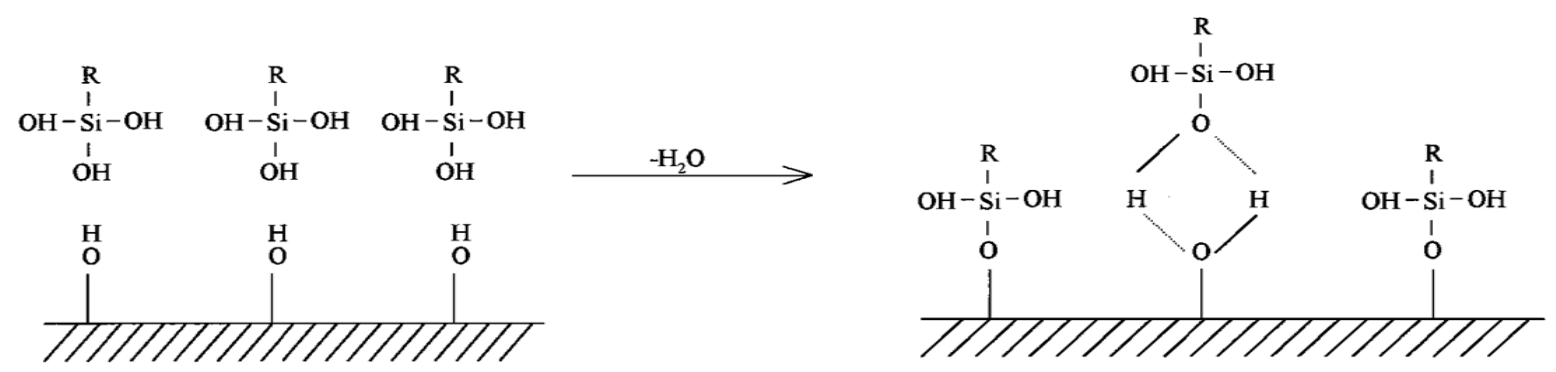

Figure 1. Surface structure of silane-treated glass fiber [1].

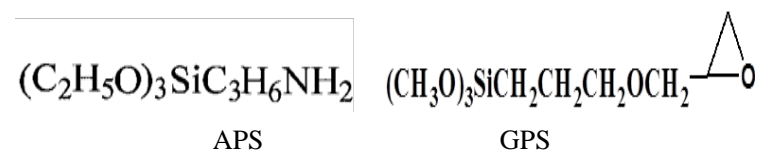

Figure 2. Chemical structures of the APS and GPS. 


\subsection{Composite Film Fabrication}

Based on APS treated glass fiber, GPS treated glass fiber, and non-treated glass fiber (burned original glass fiber), three composite films were fabricated. The procedure described below (Figure 3).

1) Matrix resin was prepared by complete mixing with fluorene acrylate, urethane acrylate, and HCPK. 2) Glass fiber was placed on a glass plate and impregnated with the matrix resin. 3) Sample was deaerated in a vacuum oven at $60^{\circ} \mathrm{C}$ for $20 \mathrm{~min}$. 4) The drenched sample was covered with another glass plate. 5) To obtain a proper film thickness, the sample was pressed by laminator. 6) Sample was treated by heat treatment at $220^{\circ} \mathrm{C}$ oven for $1 \mathrm{~h}$ after cured both sides by metal UV lamp for $90 \mathrm{~s}$.

\subsection{Bending Test}

Figure 4 shows schematic diagram of bending test to observe the point where delamination occurs.

This is the experiment exerted by force until the upper and bottom sides of specimen bending becomes equilibrium. At the moment specimen delamination occurs, the flexural property of composite film is estimated by measuring the distance between gap and haze.

\subsection{Scanning Electron Microscopy (SEM)}

Silanization of glass fiber surface was observed with a scanning electron microscopy (S3500N, HITACHI). The surfaces of specimens were coated with gold to avoid charging under the electron beam.

\section{Results and Discussion}

Figure 5 shows SEM microphotographs of the surface of various silane-treated glass fiber. Figure 5(a) is image of none-treated glass fiber. It has a clean surface. Figure 5(b) and Figure 5(c) are images of glass fibers treated by APS and GPS, respectively. As shown in Figure 5(b) and Figure 5(c), we found that APS and GPS are well adhered to the surface of glass fiber. This indicates that the interfacial adhesion of the glass composites is improved. These results could be explained by the increase of hydroxyl groups and it makes more hydrogen bonding at the interfaces between the glass fiber and the silane coupling agent.

Figure 6 displays hazes of composite films treated APS and GPS silane coupling agents and non-treated depending on the gap of the two plates. For composite films treated by APS and GPS coupling agents, haze started increasing when the upper and bottom side of specimen gap becomes $8 \mathrm{~mm}$. For non-treated glass fiber,

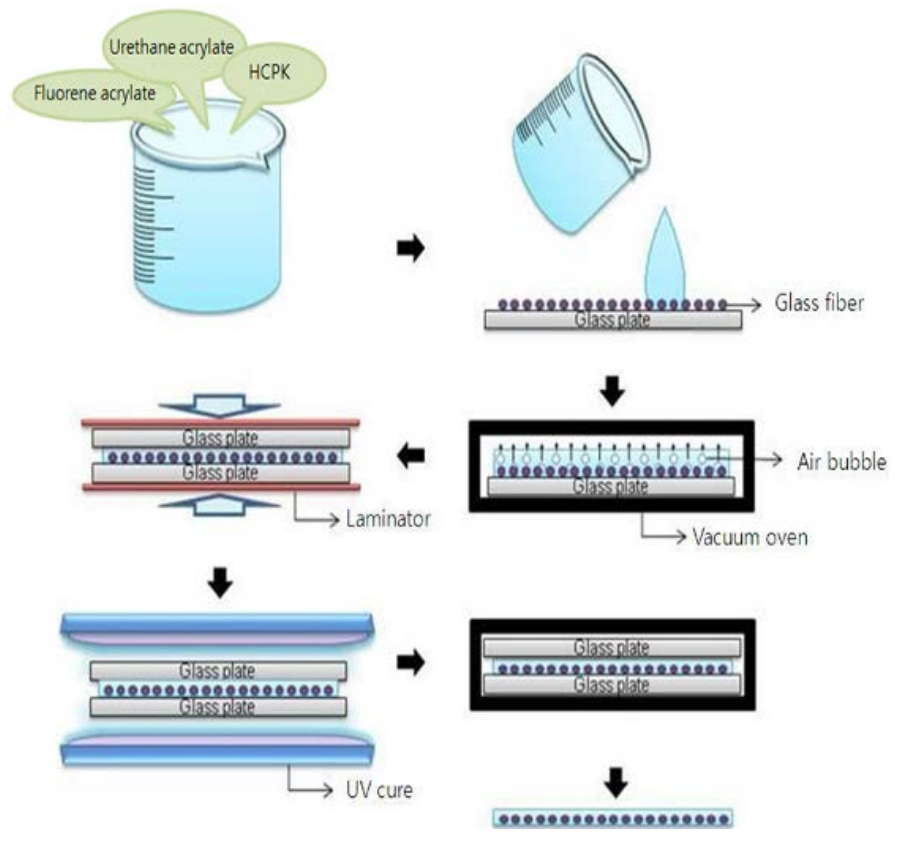

Figure 3. The manufacturing process of composite film. 


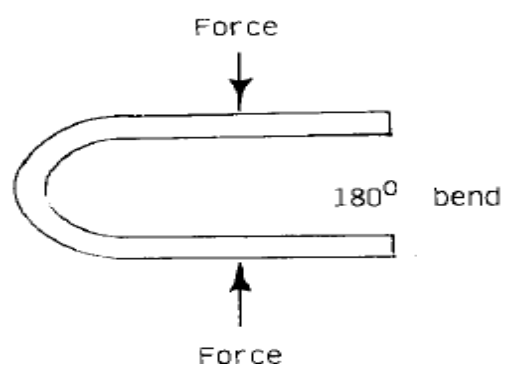

Figure 4. Standard test method for bend testing of material (ASTM E 290-97a).

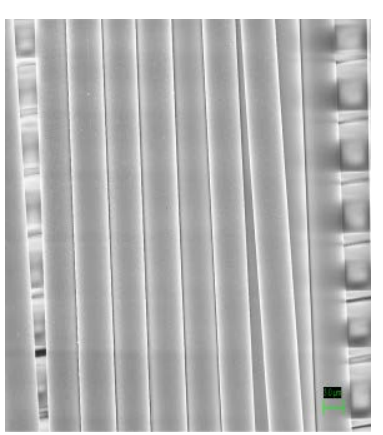

(a)

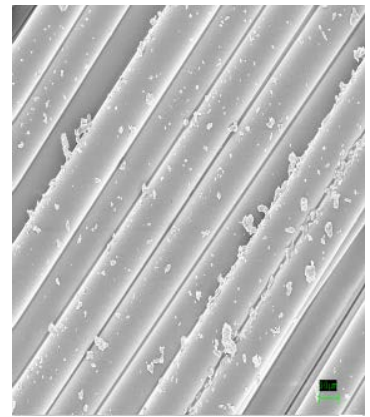

(b)

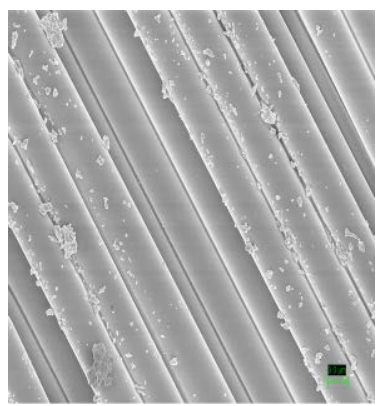

(c)

Figure 5. SEM micrographs of the glass fiber (a) non-treated glass fiber; (b) APS; and (c) GPS-treated glass fiber.

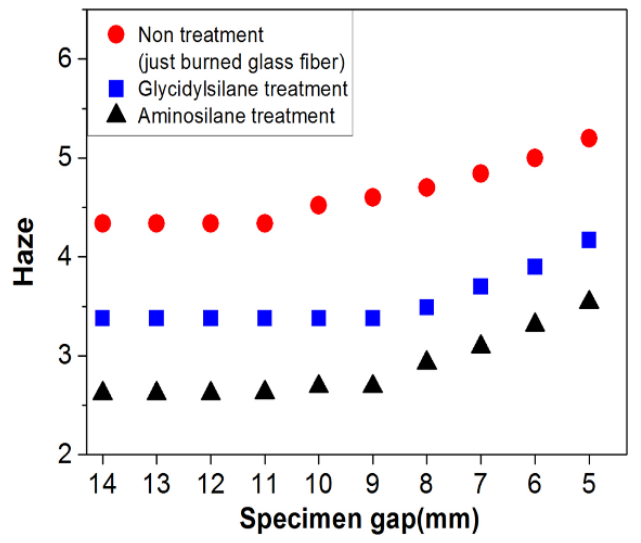

Figure 6. Hazes of composite films treated APS and GPS coupling agents and non-treated depending on the gap of the upper and bottom side of specimen. 
delamination started at $10 \mathrm{~mm}$, shows the poorest flexural property. As a result of evaluation of flexural property, the flexural property of composite film treated by APS coupling agent is the best. Result above is expected that APS treated glass fiber is well compatible with flourene acrylate and urethane acrylate applied matrix resin.

\section{Conclusion}

For the manufacture of transparent glass fiber composite film to apply for flexible device, excellent optical property and flexural property are significant elements. To improve the interfacial adhesion at interface between the glass fibers and matrix resin, the various types of silane coupling agents such as $\gamma$-aminopropyl triethoxy silane (APS) and $\gamma$-glycid oxypropyl trimethoxy silane (GPS) were applied. In result, the optical property and flexural property of glass fiber composite film were highly improved by the treatment of silane coupling agent between glass fiber and matrix resin. And APS coupling agent was suitable in this study.

\section{Acknowledgements}

This work was supported by the BK21 PLUS Centre for Advanced Chemical Technology (21A20131800002).

\section{References}

[1] Park, S.-J. and Jin, J.-S. (2001) Effect of Silane Coupling Agent on Interphase and Performance of Glass Fiber/Unsaturated Polyester Compoiste. Journal of Colloid and Interface Science, 242, 174-179. http://dx.doi.org/10.1006/jcis.2001.7788

[2] Ryu, S.C., Kim, J.W. and Park, L.S. (2009) Fabrication of Glass Fiber Reinforced Composite Film for Flexible Organic Light Emitting Diode Devices. Mol. Cryst. Liq. Cryst., 514, 331-343.

[3] Agrawal, R., Saxena, N.S., Sreekala, M.S. and Thomas, S. (2000) Effect of Treatment on the Thermal Conductivity and Thermal Iffusivity of Oil-Palm-Giber-Reinforced Phenolformaldehyde Composites. Journal of Polymer Science Part B: Polymer Physics, 38, 916-921. http://dx.doi.org/10.1002/(SICI)1099-0488(20000401)38:7<916::AID-POLB2>3.3.CO;2-S

[4] Mäder, E. and Pisanova, E. (2000) Characterization and Design of Interphases in Glass Giber Reinforced Polyproplyene. Polymer Composites, 21, 361-368. http://dx.doi.org/10.1002/pc.10194

[5] Elley-Bristow, D.M., Bellinger, M.A., Sauer, J.A. and Hara, M. (1999) Interfacial Bonding of Silica Glass Giber to Polystyrene Ionomers. Journal of Polymer Science Part B: Polymer Physics, 37, 2705-2710. http://dx.doi.org/10.1002/(SICI)1099-0488(19990915)37:18<2705::AID-POLB14>3.0.CO;2-C

[6] Bayer, T., Eichhorn, K.-J., Grundke, K. and Jacobasch, H.-J. (1999) FTIR Spectroscopic Studies of Interfacial Reactions between Amino Functionalized Silicon Surfaces and Molten Maleic Anhydride Copolymers. Macromolecular Chemistry and Physics, 200, 852-857.

[7] Tragoonwichian, S., Yanumet, N. and Ishida, H. (2006) Effect of Fiber Surface Modification on the Mechanical Properties of Sisal Fiber-Reinforced Benzoxazine/Epoxy Composites Based on Aliphatic Diamine Benzoxazine. Journal of Applied Polymer Science, 106, 2925-2935. http://dx.doi.org/10.1002/app.25797

[8] Shibahara, S., Shimobe, Y. and Kuramoto, H. EP Patent NO.1477529A1. 